\title{
Global and Widespread Local White Matter Abnormalities in Juvenile Neuronal Ceroid Lipofuscinosis
}

(D) Roine, (D)T.J. Roine, (D)A. Hakkarainen, (D)A. Tokola, D M.H. Balk, (D) M. Mannerkoski, DL.E. Åberg, (D)T. Lönnqvist, and (D)T. Autti

\begin{abstract}
BACKGROUND AND PURPOSE: Juvenile neuronal ceroid lipofuscinosis is a progressive neurodegenerative lysosomal storage disease of childhood. It manifests with loss of vision, seizures, and loss of cognitive and motor functions leading to premature death. Previous MR imaging studies have reported cerebral and cerebellar atrophy, progressive hippocampal atrophy, thalamic signal intensity alterations, and decreased white matter volume in the corona radiata. However, conventional MR imaging findings are usually normal at younger than 10 years of age. The purpose of our study was to investigate whether diffusion MR imaging could reveal changes in white matter microstructure already present at a younger age.
\end{abstract}

MATERIALS AND METHODS: We investigated global and local white matter abnormalities in 14 children with juvenile neuronal ceroid lipofuscinosis (mean age, $9.6 \pm 3.4$ years; 10 boys) and 14 control subjects (mean age, $11.2 \pm 2.3$ years; 7 boys). Twelve patients underwent follow-up MR imaging after 2 years (mean age, $11.4 \pm 3.2$ years; 8 boys). We performed a global analysis using 2 approaches: white matter tract skeleton and constrained spherical deconvolution-based whole-brain tractography. Then, we investigated local microstructural abnormalities using Tract-Based Spatial Statistics.

RESULTS: We found globally decreased anisotropy $(P=.000001)$ and increased diffusivity $(P=.001)$ in patients with juvenile neuronal ceroid lipofuscinosis. In addition, we found widespread increased diffusivity and decreased anisotropy in, for example, the corona radiata $(P<.001)$ and posterior thalamic radiation $(P<.001)$. However, we found no differences between the first and second acquisitions.

CONCLUSIONS: The patients with juvenile neuronal ceroid lipofuscinosis exhibited global and local abnormalities in white matter microstructure. Future studies could apply more specific microstructural models and study whether these abnormalities are already present at a younger age.

ABBREVIATIONS: $A D=$ axial diffusivity; $C L N 3=$ juvenile neuronal ceroid lipofuscinosis; $C P=$ coefficient of planarity; $F A=$ fractional anisotropy; $M D=$ mean diffusivity; $\mathrm{NCL}$ = neuronal ceroid lipofuscinosis; $\mathrm{RD}$ = radial diffusivity; TBSS = Tract-Based Spatial Statistics

J uvenile neuronal ceroid lipofuscinosis (CLN3) is a rare, progressive neurodegenerative lysosomal storage disease, in which autofluorescent ceroid lipopigments accumulate in the lysosomes. The first clinical symptom, rapidly progressive vision fail-

Received November 22, 2017; accepted after revision April 11, 2018.

From the Department of Radiology (U.R., T.J.R., A.H., A.T., M.H.B., T.A.), HUS Medical Imaging Center, and Departments of Child Psychiatry (M.M.) and Psychiatry (L.E.Å), University of Helsinki and Helsinki University Hospital, Helsinki, Finland; imec-Vision Lab (T.J.R.), Department of Physics, University of Antwerp, Wilrijk (Antwerp), Belgium; and Department of Child Neurology (T.L.), Children's Hospital, University of Helsinki and Helsinki University Hospital, Helsinki, Finland.

This work was supported by Noah's Hope/Hope 4 Bridget, the Thisbe and Noah Scott Foundation, the Batten Disease Support and Research Association, Finnish Brain Foundation, Paulo Foundation, and Emil Aaltonen Foundation.

Please address correspondence to Ulrika Roine, MD, HUS Medical Imaging Center, Radiology, University of Helsinki and Helsinki University Hospital, PL 22 (Haartmaninkatu 4), FI-00014 Helsingin Yliopisto, Finland; e-mail: ulrika.roine@helsinki.fi; @UlrikaRoine ure leading to blindness, appears around $4-10$ years of age. ${ }^{1-3}$ It is followed by deterioration in cognitive and motor functions, in which the cognitive decline becomes clearer around $8-12$ years of age. ${ }^{1}$ Other symptoms include ataxia, dysarthria, rigidity, and difficulty in initiating movement, and occasionally, there are pyramidal signs. ${ }^{1}$ The patients start having epileptic seizures typically around 10 years of age. ${ }^{4}$ Psychiatric symptoms, such as depression and psychosis, are also common. ${ }^{5}$ Although the clinical course is variable, the disease eventually leads to premature death in the second or third decade of life. ${ }^{6}$

More than 400 mutations in 14 genes have been found in children with neuronal ceroid lipofuscinoses. ${ }^{7,8}$ The juvenile form is the most common, with a reported incidence of $2-7 / 100,000$

Indicates article with supplemental on-line tables.

http://dx.doi.org/10.3174/ajnr.A5687

AJNR Am J Neuroradiol 39:1349-54 Jul 2018 www.ajnr.org 
births in Scandinavia ${ }^{9}$ and $0.2-1.5 / 100,000$ in Central Europe. ${ }^{10,11}$ In Canada, the estimated incidence is $0.6 / 100,000$ births. ${ }^{12}$ The disease is caused by the recessive inheritance of mutations in the CLN3 gene located on chromosome 16p12, encoding a membrane protein CLN3. ${ }^{13}$

The presence of ocular abnormalities and vacuolated lymphocytes in peripheral blood is suggestive of the disease, and the diagnosis can typically be confirmed by CLN3 mutation analysis. ${ }^{14}$

Conventional MR imaging findings are usually normal at younger than 10 years of age. ${ }^{15}$ Previous MR imaging studies have reported cerebral and cerebellar atrophy, progressive hippocampal atrophy, decreased gray matter volume in the dorsomedial part of the thalami, and decreased white matter volume in the corona radiata in patients with CLN3. ${ }^{15-17}$ However, cerebral atrophy is mostly seen in patients older than 14 years of age, and cerebellar atrophy, even later. ${ }^{15}$ In a postmortem study, higher MR imaging signal intensity of the periventricular white matter was reported with histologically observed severe periventricular loss of myelin and gliosis. ${ }^{18}$ Thalamic alterations have been consistently found in several types of neuronal ceroid lipofuscinosis (NCL), including CLN1 (infantile NCL), CLN2 (classic late infantile NCL), CLN3 (juvenile NCL), CLN5 (Finnish-variant late infantile NCL), and CLN7 (Turkish-variant late infantile NCL). ${ }^{19}$ Decreased T2-weighted signal intensity in the thalamus was also reported in a retrospective study in $33 \%$ of 43 patients with NCL. ${ }^{20}$ Of the 11 patients with CLN3, four had T2 hypointensity in the thalamus. Moreover, MR imaging and CT showed diffuse cerebral and cerebellar atrophy, and electroencephalography findings were abnormal in $90 \%$ of the patients.

Diffusion-weighted imaging is a noninvasive method that enables the investigation of the white matter microstructure in the brain. $^{21,22}$ In an unrestricted space, the diffusion of water molecules is equal in all directions and is thus called "isotropic," but in nerve fibers, the cell membranes restrict the diffusion of the molecules and the diffusion becomes anisotropic. Fractional anisotropy (FA) is the most commonly used index to quantify the degree of anisotropy. ${ }^{23}$ Mean diffusivity (MD) or ADC is the average diffusivity over all directions, axial diffusivity (AD) describes the diffusivity along the nerve fiber, and radial diffusivity (RD), perpendicular to it.

DW-MRI has previously revealed increased ADC values in patients with late infantile NCL. ${ }^{24}$ Furthermore, ADC values correlated with patient age and disease duration, but the correlation with the central nervous system disability scale was much weaker.

The aim of this study was to investigate global and local white matter abnormalities in CLN3. We hypothesized that DW-MRI would be more sensitive in detecting microstructural white matter abnormalities than conventional MR imaging. We investigated global white matter microstructure with 2 approaches: 1 ) by performing whole-brain tractography, ie, the reconstruction of the white matter tracts in the brain ${ }^{25}$; and 2) by reconstructing a white matter tract skeleton. ${ }^{26}$ With DTI-based tractography, ${ }^{27,28}$ it is not possible to detect crossing fibers. ${ }^{29,30}$ Thus, we used constrained spherical deconvolution-based tractography, ${ }^{25,31,32}$ which enables the reliable reconstruction of neural tracts through regions with complex (eg, crossing) fiber configurations, ${ }^{33-35}$ present in most white matter voxels. ${ }^{36}$ Finally, we used TractBased Spatial Statistics (TBSS; http://fsl.fmrib.ox.ac.uk/fsl/ fslwiki/TBSS) to investigate local microstructural properties in the same subjects. ${ }^{26}$

\section{MATERIALS AND METHODS \\ Participants}

We acquired DW-MRI data from 14 patients with CLN3 and 14 age-matched controls. Twelve of the 14 patients underwent follow-up MR imaging after 2 years on average. MR imaging was performed at the Helsinki University Central Hospital, Finland, from 2007 to 2014. During the first acquisition, the mean age of the patients was $9.6 \pm 3.4$ years, and during the second acquisition, it was $11.4 \pm 3.2$ years. The mean age of control subjects was $11.2 \pm 2.3$ years. The difference in age was not statistically significant between patients and controls in the first or second acquisition. Seventy-one percent of the patients were males in the first acquisition, and $67 \%$, in the second acquisition. Fifty percent of the controls were males. In addition, we collected disease-severity information using the Unified Parkinson's Disease Rating Scale, Part III, ${ }^{37}$ a clinician-scored monitored motor evaluation, from 13 of the 14 patients for the first acquisition and 11 of the 12 patients for the second acquisition. Only the youngest patient had visual function close to normal at the time of the first acquisition; the remainder were blind or almost blind.

The patients with CLN3 were diagnosed on the basis of their clinical symptoms, including deterioration of vision and typical ophthalmologic findings, and the diagnoses were confirmed by DNA analysis. Nine patients were homozygous for the main mutation (1.02kb deletion including amino acids in exons 7 and 8). Four patients were heterogeneous for the major mutation and a minor mutation ( $3 \mathrm{~kb}$ deletion including amino acids in exons $10-13)$. One patient was heterozygous for the main mutation and a single nucleotide mutation in exon 13. The symptoms of this patient differed from others because she was blind, but her cognitive profile was normal. Depending on the patient, symptomatic medication typical for the disease was in use, including citalopram, valproate, levetiracetam, and risperidone. In addition, most patients participated in a concurrent study testing simvastatin in CLN3 for 1-2 years. The patients were recruited from the Department of Child Neurology, Helsinki University Central Hospital, and the control subjects were healthy volunteers recruited for this study. The Ethics Committee for Gynaecology and Obstetrics, Pediatrics, and Psychiatry of the Hospital District of Helsinki and Uusimaa approved the research protocol, and a guardian of each participant signed a written informed consent form before the study.

\section{Data Acquisition}

The MR imaging data were acquired with an Achieva 3T machine (Philips Healthcare, Best, the Netherlands) with an 8-channel head coil, using a $2 \times 2 \times 2 \mathrm{~mm}$ voxel size and 32 gradient orientations with diffusion-weighting of $1000 \mathrm{~s} / \mathrm{mm}^{2}$. In addition, 1 non-DWI was acquired. The FOV was $224 \times 224 \times 160$ $\mathrm{mm}$, and 80 axial slices were acquired. The TE was $59.5 \mathrm{~ms}$, and TR was 10.809 seconds. T1-weighted anatomic 3D images were acquired with a resolution of $1 \times 1 \times 1 \mathrm{~mm}$. The FOV was 
Table 1: Global microstructural differences between children with CLN3 and age-matched control group with both skeleton and tractography approaches

\begin{tabular}{|c|c|c|c|c|c|c|}
\hline Measure & Control & CLN3 1st & CLN3 2nd & $\begin{array}{c}P \text { Value } \\
\text { (CLN3 lst } \\
\text { vs Control) }\end{array}$ & $\begin{array}{c}P \text { Value } \\
\text { (CLN3 2nd } \\
\text { vs Control) }\end{array}$ & $\begin{array}{c}P \text { Value }{ }^{a} \\
\text { (CLN3 1st } \\
\text { vs CLN3 2nd) }\end{array}$ \\
\hline FA (skeleton) & $.328 \pm .026$ & $.297 \pm .021$ & $.288 \pm .029$ & $<.001^{\mathrm{b}}$ & $<.001^{\mathrm{b}}$ & .95 \\
\hline FA (tractogram) & $.271 \pm .019$ & $.233 \pm .016$ & $.224 \pm .021$ & $.000001^{\mathrm{b}}$ & $.000001^{\mathrm{b}}$ & .82 \\
\hline MD (skeleton) & $.965 \times 10^{-3} \pm .0582 \times 10^{-3}$ & $1.011 \times 10^{-3} \pm .0806 \times 10^{-3}$ & $1.057 \times 10^{-3} \pm .119 \times 10^{-3}$ & $.01^{\mathrm{b}}$ & $.005^{\mathrm{b}}$ & .89 \\
\hline MD (tractogram) & $.957 \times 10^{-3} \pm .0506 \times 10^{-3}$ & $1.036 \times 10^{-3} \pm .0882 \times 10^{-3}$ & $1.108 \times 10^{-3} \pm .131 \times 10^{-3}$ & $<.001^{\mathrm{b}}$ & $<.001^{\mathrm{b}}$ & .43 \\
\hline $\mathrm{AD}$ (skeleton) & $1.29 \times 10^{-3} \pm .0614 \times 10^{-3}$ & $1.31 \times 10^{-3} \pm .0769 \times 10^{-3}$ & $1.36 \times 10^{-3} \pm .112 \times 10^{-3}$ & .12 & $.04^{\mathrm{b}}$ & .83 \\
\hline AD (tractogram) & $1.22 \times 10^{-3} \pm .0506 \times 10^{-3}$ & $1.28 \times 10^{-3} \pm .0803 \times 10^{-3}$ & $1.34 \times 10^{-3} \pm .122 \times 10^{-3}$ & $.008^{b}$ & $<.001^{\mathrm{b}}$ & .39 \\
\hline RD (skeleton) & $.801 \times 10^{-3} \pm .0578 \times 10^{-3}$ & $.859 \times 10^{-3} \pm .0849 \times 10^{-3}$ & $.907 \times 10^{-3} \pm .126 \times 10^{-3}$ & $.003^{b}$ & $.002^{\mathrm{b}}$ & .93 \\
\hline $\mathrm{RD}$ (tractogram) & $.823 \times 10^{-3} \pm .0512 \times 10^{-3}$ & $.917 \times 10^{-3} \pm .0927 \times 10^{-3}$ & $.990 \times 10^{-3} \pm .136 \times 10^{-3}$ & $<.001^{\mathrm{b}}$ & $<.001^{\mathrm{b}}$ & .45 \\
\hline $\mathrm{CP}$ (skeleton) & $.169 \pm .0135$ & $.163 \pm .0125$ & $.157 \pm .0146$ & $.04^{\mathrm{b}}$ & $.03^{\mathrm{b}}$ & .73 \\
\hline $\mathrm{CP}$ (tractogram) & $.141 \pm .0113$ & $.129 \pm .00633$ & $.126 \pm .00866$ & $<.001^{\mathrm{b}}$ & $<.001^{\mathrm{b}}$ & .93 \\
\hline
\end{tabular}

${ }^{a}$ Age and sex were used as covariates.

b Significant.

$256 \times 256 \times 170 \mathrm{~mm}$, TR was $8.3 \mathrm{~ms}$, TE was $3.8 \mathrm{~ms}$, and the flip angle was $8^{\circ}$. In addition, T2-weighted images were acquired with a resolution of $0.5 \times 0.5 \times 4.4 \mathrm{~mm}$; for 8 of the 12 patients in the second acquisition, fluid-attenuated inversion recovery images were acquired with a resolution of $0.4 \times 0.4 \times$ $4.4 \mathrm{~mm}$.

\section{Visual Analysis}

The size of the cerebral sulci and the ventricles was classified as normal, mildly enlarged, moderately enlarged, or severely enlarged. All signal intensity abnormalities were recorded. The midsagittal area of the corpus callosum was measured. ${ }^{38}$

\section{Global Microstructural Analysis}

Whole-brain probabilistic tractography was performed to reconstruct fiber tracts with constrained spherical deconvolution in ExploreDTI (http://exploredti.com/). ${ }^{25,32,39}$ The DWIs were corrected for subject motion and eddy current and echo-planar imaging-induced distortions, ${ }^{40,41}$ after which the fiber orientation distribution functions were estimated with constrained spherical deconvolution. ${ }^{32}$ Spheric harmonics up to the fourth order were used in the estimation. Streamline tractography was then performed in native space for all subjects. ${ }^{25}$ A seed point resolution of $1 \times 1 \times 1 \mathrm{~mm}$, a fiber orientation distribution threshold of 0.1 , a step size of $1 \mathrm{~mm}$, and a maximum angle deviation of $45^{\circ}$ were used. The minimum length of the fiber was set to $50 \mathrm{~mm}$.

Finally, a streamline density-weighted mean FA value was calculated by weighting the FA value of all voxels with the number of streamlines passing through the voxel and dividing by the sum of all streamline counts. Mean values for $\mathrm{MD}, \mathrm{AD}, \mathrm{RD}$, and the coefficient of planarity $(\mathrm{CP})$ were calculated in the same way. CP can be used to quantify the degree of fiber complexity. ${ }^{42}$ A higher CP describes a more disc-shaped diffusion tensor, typically caused by crossing fibers. ${ }^{43-45}$

In addition, an FA skeleton was reconstructed for all subjects as introduced in TBSS. $^{26}$ The mean values for FA, MD, AD, RD, and $\mathrm{CP}$ were then calculated across the skeleton.

The relationship between disease severity and the global microstructural parameters was investigated by calculating correlations both with and without age and sex as covariates.

Statistical analyses were performed in SPSS (IBM, Armonk, New York) with a general linear model using age and sex as covariates. The homoscedasticity of the residuals was verified visually,

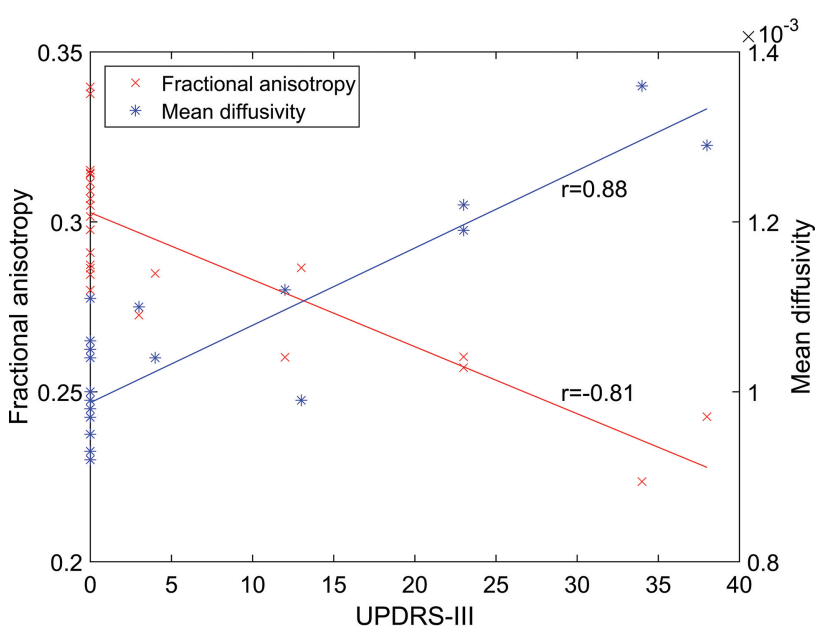

FIG 1. The relationship between disease severity measured by the Unified Parkinson's Disease Rating Scale (UPDRS), Part III, and fractional anisotropy $(A)$ and mean diffusivity $(B)$ calculated from the whole-brain white matter tract skeleton.

and the equality of error variances was confirmed using the Levene test. The significance threshold was $P<.05$.

\section{Local Microstructural Analysis}

The voxelwise microstructural analysis was performed using TBSS, ${ }^{26}$ which belongs to the FMRIB Software Library tools (FSL; http://www.fmrib.ox.ac.uk/fsl). ${ }^{46}$ Subject motion and eddy current-induced distortions were corrected with the eddy tool (https://fsl.fmrib.ox.ac.uk/fsl/fslwiki/eddy), ${ }^{47}$ after which the diffusion tensors were fitted. To reconstruct a mean FA skeleton, we transformed FA images into the subject space of the most representative subject by nonlinear registration based on free-form deformations and B-splines, after which a mean FA image of all subjects was calculated and thinned. ${ }^{26}$ Finally, the individual subject's skeleton was projected onto the mean FA skeleton. For MD, $\mathrm{AD}, \mathrm{RD}$, and $\mathrm{CP}$, we used the same nonlinear warps and projection vectors as used for FA images. Randomise (http://fsl.fmrib.ox.ac.uk/ fsl/fslwiki/Randomise), a permutation program, was used for statistical testing of the voxelwise differences between patients and controls with 5000 permutations. Clusterlike structures in the data were enhanced with threshold-free cluster enhancement, and multiple correction for the family-wise error rate with a significance threshold of $P<.05$ was performed using permutation-based nonparametric testing. ${ }^{48}$ 


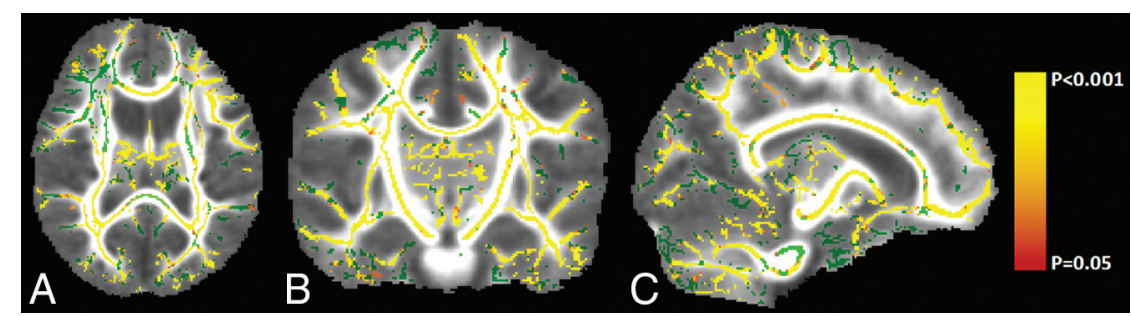

FIG 2. Tract-Based Spatial Statistics results for decreased fractional anisotropy in patients with juvenile neuronal ceroid lipofuscinosis visualized on axial ( $A$ ), coronal (B), and sagittal (C) slices. The white matter tract skeleton is visualized in green, and the significant results are visualized from red $(P=.05)$ to yellow $(P<.001)$. Fractional anisotropy values are significantly $(P<.001)$ decreased in many areas such as the corpus callosum, corticospinal tracts, corona radiata, and superior longitudinal fasciculi.

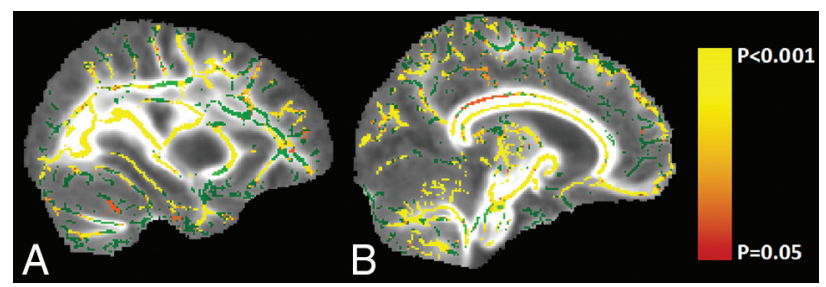

FIG 3. Decreased fractional anisotropy in patients with juvenile neuronal ceroid lipofuscinosis in, for example, the left posterior thalamic radiation $(P<.001)$ and left posterior corona radiata $(P<.001)$ on sagittal slices $58(A)$ and $79(B)$. The white matter tract skeleton is visualized in green, and significant results are visualized from red $(P=$ $.05)$ to yellow $(P<.001)$.

\section{RESULTS}

\section{Conventional MR Imaging Findings}

Conventional MR imaging was considered normal in most subjects (On-line Table 1). The size of the ventricles was increased in 2 of the 14 patients during the first MR imaging and for 4 of the 11 patients during the second MR imaging. Thinning of the corpus callosum was observed in 2 of the 14 patients in the first MR imaging and 3 of the 11 patients in the second MR imaging. ${ }^{38}$ Abnormal periventricular signal intensity was not present in the T1- or T2-weighted images. However, in FLAIR images, an increase in the periventricular signal intensity was observed for the 8 patients who underwent FLAIR in the second acquisition. The conventional MR imaging findings are further described in On-line Table 1.

\section{Global Microstructural Analyses}

We found significantly decreased FA and CP values and significantly increased $\mathrm{AD}, \mathrm{RD}$, and $\mathrm{MD}$ values in patients compared with the control group, as shown in Table 1. These differences were found with both the tractography and the skeleton approach. The largest relative difference was in the FA values using the tractography approach $(-15 \%$ difference) $(P=.000001)$.

We found significant differences in both acquisitions of patients with CLN3 compared with controls. However, there were no significant differences between the 2 acquisitions of the patients. The analyses between the 2 acquisitions were repeated without using age as a covariate, resulting in no significant differences. The effect of age was significant $(P=.006-.044)$ for all dependent variables except for the CP tractogram.

Correlation analyses between the global microstructural parameters from the white matter skeleton and disease severity showed significant negative correlations for FA $(r=-0.81, P=$
$.000001)$ and $\mathrm{CP}(r=-0.66, P=.0005)$, and significant positive correlations between the diffusivity parameters $(P<$ $.0000001)$ and disease severity. The relationships of FA and MD with respect to disease severity are shown in Fig 1. The correlation coefficients between the global microstructural parameters and disease severity are presented in On-line Table 2.

\section{Local Microstructural Analysis}

The local microstructural analysis performed with TBSS revealed widespread voxelwise decreases in FA as shown in Fig 2, for example, in the corona radiata $(P<.001)$ and posterior thalamic radiation $(P<.001)$, as shown in Fig 3. In addition, MD, $\mathrm{AD}$, and $\mathrm{RD}$ were increased and $\mathrm{CP}$ was decreased in many regions. The results for MD are shown in Fig 4.

\section{DISCUSSION}

In a visual analysis of conventional MR imaging of patients with CLN3, an increase in T2-weighted signal intensity of periventricular white matter may be observed, sometimes even before 10 years of age. ${ }^{18}$ Later, decreased white matter volume and increased white matter signal intensity due to gliosis can be seen. ${ }^{17}$ Related to the general brain atrophy, thinning of the corpus callosum is also present in CLN3. ${ }^{15}$

In this study, we investigated CLN3 for the first time with DW-MRI. For the global analyses, we used 2 different approaches, fiber tractography and white matter tract skeleton. We found widely distributed abnormalities in the white matter microstructure in patients with CLN3 compared with age-matched controls, and these abnormalities were seen at both the global and local level. However, there were no differences between the first and second acquisitions of patients with CLN3, suggesting that the microstructural changes do not progress rapidly and thus might be already present in early childhood.

More specifically, we found significantly decreased FA values in patients with CLN3 widely distributed across the whole brain. Intact cell membranes and dense packing of axons are the primary cause of anisotropic diffusion. ${ }^{23}$ However, other properties such as myelination can also affect the degree of anisotropy. ${ }^{29,43} \mathrm{Be}-$ cause the complexity of the underlying white matter fiber structure can also affect the $\mathrm{FA},{ }^{29}$ we compared the $\mathrm{CP}$ values between patients and controls. CP was decreased in patients with CLN3 compared with controls, suggesting that they would have a lower degree of crossing fibers than the controls. Thus, the lower FA in patients was not explained by more crossing fibers.

Increased MD in patients with CLN3 is in accordance with the previous DW-MRI study performed in patients with late infantile NCL, in which whole-brain ADC values correlated positively with age and disease severity, whereas in control subjects, ADC values decreased with age. ${ }^{24}$ In another study, quantitative T2 values have been investigated in CLN2 and CLN3 ${ }^{49}$ In patients with CLN2, there were elevated quantitative T2 values, but in CLN3, there were no differences in any of the white matter ROIs compared with controls. This finding suggests that DW-MRI is re- 


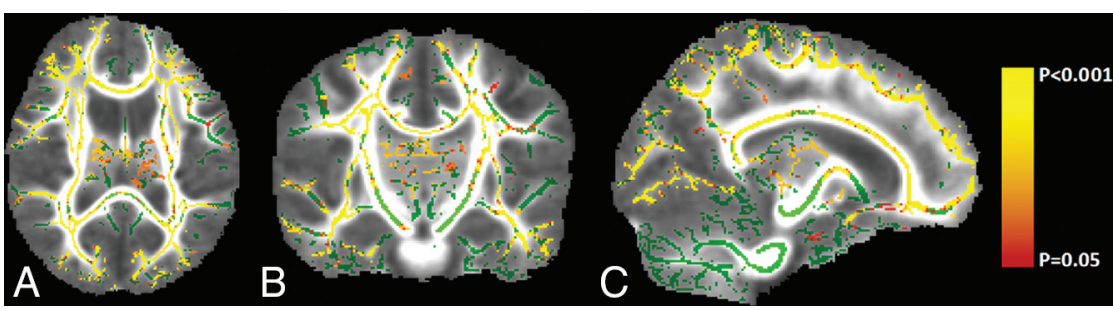

FIG 4. Tract-Based Spatial Statistics results for increased mean diffusivity in patients with juvenile neuronal ceroid lipofuscinosis visualized on axial $(A)$, coronal (B), and sagittal $(C)$ slices. The white matter tract skeleton is visualized in green, and the significant results are visualized from red $(P=$ $.05)$ to yellow $(P<.001)$. Multiple areas but not as many as for fractional anisotropy (Fig 2$)$ have significantly $(P<.001)$ increased mean diffusivity values. matter microstructural differences should be investigated with more detailed microstructural models.

Our results indicate that in patients with CLN3, the microstructural brain abnormalities are already present before 10 years of age and do not progress rapidly in the prepubertal stage. Considering that most of the conventional MR imaging findings manifest at an older age, we believe that specific microstructural abnormalities could also be revealed in other similar diseases using diffusion MR imaging. quired to detect the widespread microstructural changes in the white matter of patients with CLN3.

In addition, we looked at $\mathrm{AD}$ and $\mathrm{RD}$ values. Both $\mathrm{AD}$ and $\mathrm{RD}$ were increased in CLN3, but the absolute increase in RD (for the skeleton approach +0.06 ) was higher than in $\mathrm{AD}$ (for the skeleton approach +0.02 ), which is consistent with a decrease in FA.

Previous MR imaging findings suggest that there are thalamic alterations in lysosomal storage diseases, including CLN3. ${ }^{16-20}$ In our study, TBSS showed decreased FA in several tracts, including the anterior and posterior thalamic radiations. Decreased white matter volume in the corona radiata has been found earlier in CLN3. ${ }^{16}$ In our study, TBSS showed a decrease in FA in the posterior corona radiata. However, more specific analyses, such as a tractography reconstruction of the fiber bundles, potentially impaired in CLN3, could reveal more specific information about the microstructural and connectivity abnormalities than TBSS.

The patients with CLN3 underwent a follow-up MR imaging after 2 years. No significant differences between the 2 acquisitions of patients were found, suggesting that the microstructural changes do not progress rapidly in the prepubertal stage but might instead be present already in early childhood, though conventional MR imaging findings are usually normal in visual analysis at younger than 10 years of age. ${ }^{15}$

Limitations of this study include a relatively small sample size. However, we used several methods that produced similar results. In addition, we used constrained spherical deconvolution-based tractography in the global analyses, though its acquisition was suboptimal because the diffusion-weighting and the number of gradient orientations were relatively low. ${ }^{50,51}$ However, fiber crossings are present in most white matter ${ }^{36}$ and can be reliably identified with constrained spherical deconvolution. ${ }^{32-35}$ Moreover, TBSS has limitations, for example, concerning the parameters selected by the user-that is, sensitivity, anatomic specificity, and restriction to only a part of the white matter voxels. ${ }^{52}$

\section{CONCLUSIONS}

We found widespread microstructural white matter abnormalities in both acquisitions of patients with CLN3 compared with healthy controls. However, no significant differences were observed between the 2 acquisitions of the patients. Local microstructural abnormalities were investigated with TBSS, showing widespread abnormalities. In the future, more specific analyses are needed to investigate certain regions more thoroughly, such as the thalami, or white matter tracts related to those regions. Furthermore, the specific nature of the white
Disclosures: Ulrika Roine-RELATED: Grant: Batten Disease Support and Research Association, Comments: $\$ 50,000$ funding from the foundation awarded to the University of Helsinki for this project.* Timo J. Roine_-RELATED: Grant: Batten Disease Support and Research Association, Comments: Grant of $\$ 50,000$ awarded for this work to the University of Helsinki*; UNRELATED: Grants/Grants Pending: Emil Aaltonen Foundation, Finland, Comments: grant for a postdoctoral research project from December 2017 to November 2018 concerning the development and reproducibility of novel diffusion MRI analysis methods. Marja H. Balk—UNRELATED: Employment: HUS Medical Imaging Center, Comments: full-time job. Laura E. ÅbergUNRELATED: Employment: normal work in the Neuropsychiatric Clinic, Hospital District of Helsinki and Uusimaa. Tuula Lönnqvist-UNRELATED: Payment for Development of Educational Presentations: Actelion Pharmaceuticals Sverige $A B$, Comments: Lysosomal Storage Disease Academy in April 2017, Tampere, Finland. Taina Autti—RELATED: Grant: Batten Disease Support and Research Association.* *Money paid to the institution.

\section{REFERENCES}

1. Santavuori P, Lauronen L, Kirveskari K, et al. Neuronal ceroid lipofuscinoses in childhood. Suppl Clin Neurophysiol 2000;53:443-51 CrossRef Medline

2. Collins J, Holder GE, Herbert H, et al. Batten disease: features to facilitate early diagnosis. Br JOphthalmol 2006;90:1119-24 CrossRef Medline

3. Spalton DJ, Taylor DS, Sanders MD. Juvenile Batten's disease: an ophthalmological assessment of 26 patients. Br J Ophthalmol 1980; 64:726-32 CrossRef Medline

4. Järvelä I, Autti T, Lamminranta S, et al. Clinical and magnetic resonance imaging findings in Batten disease: analysis of the major mutation (1.02-kb deletion). Ann Neurol 1997;42:799-802 CrossRef Medline

5. Santavuori P, Linnankivi T, Jaeken J, et al. Psychological symptoms and sleep disturbances in neuronal ceroid-lipofuscinoses (NCL). J Inherit Metab Dis 1993;16:245-48 CrossRef Medline

6. Jalanko A, Braulke T. Neuronal ceroid lipofuscinoses. Biochim Biophys Acta 2009;1793:697-709 CrossRef Medline

7. Miller JN, Chan CH, Pearce DA. The role of nonsense-mediated decay in neuronal ceroid lipofuscinosis. Hum Mol Genet 2013;22: 2723-34 CrossRef Medline

8. Kousi M, Lehesjoki AE, Mole SE. Update of the mutation spectrum and clinical correlations of over 360 mutations in eight genes that underlie the neuronal ceroid lipofuscinoses. Hum Mutat 2012;33: 42-63 CrossRef Medline

9. Uvebrant P, Hagberg B. Neuronal ceroid lipofuscinoses in Scandinavia: epidemiology and clinical pictures. Neuropediatrics 1997;28:6-8 CrossRef Medline

10. Claussen M, Heim P, Knispel J, et al. Incidence of neuronal ceroidlipofuscinoses in West Germany: variation of a method for studying autosomal recessive disorders. Am J Med Genet 1992;42:536-38 CrossRef Medline

11. Cardona F, Rosati E. Neuronal ceroid-lipofuscinoses in Italy: an epidemiological study. Am J Med Genet 1995;57:142-43 CrossRef Medline

12. MacLeod PM, Dolman CL, Chang E, et al. The neuronal ceroid lipo- 
fuscinoses in British Columbia: a clinical epidemiologic and ultrastructural study. Birth Defects Orig Artic Ser 1976;12:289-96 Medline

13. Lerner TJ, Boustany RM, Anderson JW, et al. Isolation of a novel gene underlying Batten disease, CLN3: the International Batten Disease Consortium. Cell 1995;82:949-57 CrossRef Medline

14. Williams RE, Aberg L, Autti T, et al. Diagnosis of the neuronal ceroid lipofuscinoses: an update. Biochim Biophys Acta 2006;1762:865-72 CrossRef Medline

15. Autti T, Raininko R, Vanhanen SL, et al. MRI of neuronal ceroid lipofuscinosis, I: cranial MRI of 30 patients with juvenile neuronal ceroid lipofuscinosis. Neuroradiology 1996;38:476-82 CrossRef Medline

16. Tokola AM, Salli EK, Åberg LE, et al. Hippocampal volumes in juvenile neuronal ceroid lipofuscinosis: a longitudinal magnetic resonance imaging study. Pediatr Neurol 2014;50:158-63 CrossRef Medline

17. Autti T, Hämäläinen J, Åberg L, et al. Thalami and corona radiata in juvenile NCL (CLN3): a voxel-based morphometric study. Eur J Neurol 2007;14:447-50 CrossRef Medline

18. Autti T, Raininko R, Santavuori P, et al. MRI of neuronal ceroid lipofuscinosis, II: postmortem MRI and histopathological study of the brain in $\mathbf{1 6}$ cases of neuronal ceroid lipofuscinosis of juvenile or late infantile type. Neuroradiology 1997;39:371-77 CrossRef Medline

19. Autti T, Joensuu R, Aberg L. Decreased T2 signal in the thalami may be a sign of lysosomal storage disease. Neuroradiology 2007;49: 571-78 CrossRef Medline

20. Jadav RH, Sinha S, Yasha TC, et al. Clinical, electrophysiological, imaging, and ultrastructural description in 68 patients with neuronal ceroid lipofuscinoses and its subtypes. Pediatr Neurol 2014;50: 85-95 CrossRef Medline

21. Basser PJ, Mattiello J, LeBihan D. MR diffusion tensor spectroscopy and imaging. Biophys J 1994;66:259-67 CrossRef Medline

22. Basser PJ, Mattiello J, LeBihan D. Estimation of the effective selfdiffusion tensor from the NMR spin echo. J Magn Reson B 1994;103: 247-54 CrossRef Medline

23. Beaulieu $C$. The basis of anisotropic water diffusion in the nervous system: a technical review. NMR Biomed 2002;15:435-55 CrossRef Medline

24. Dyke JP, Voss HU, Sondhi D, et al. Assessing disease severity in late infantile neuronal ceroid lipofuscinosis using quantitative MR diffusion-weighted imaging. AJNR Am J Neuroradiol 2007;28:1232-36 CrossRef Medline

25. Jeurissen B, Leemans A, Jones DK, et al. Probabilistic fiber tracking using the residual bootstrap with constrained spherical deconvolution. Hum Brain Mapp 2011;32:461-79 CrossRef Medline

26. Smith SM, Jenkinson M, Johansen-Berg H, et al. Tract-based spatial statistics: voxelwise analysis of multi-subject diffusion data. Neuroimage 2006;31:1487-505 CrossRef Medline

27. Basser PJ, Pajevic S, Pierpaoli $\mathrm{C}$, et al. In vivo fiber tractography using DT-MRI data. Magn Reson Med 2000;44:625-32 Medline

28. Mori S, van Zijl PC. Fiber tracking: principles and strategies-a technical review. NMR Biomed 2002;15:468-80 CrossRef Medline

29. Vos SB, Jones DK, Viergever MA, et al. Partial volume effect as a hidden covariate in DTI analyses. Neuroimage 2011;55:1566-76 CrossRef Medline

30. Tournier JD, Mori S, Leemans A. Diffusion tensor imaging and beyond. Magn Reson Med 2011;65:1532-56 CrossRef Medline

31. Tournier JD, Calamante F, Gadian DG, et al. Direct estimation of the fiber orientation density function from diffusion-weighted MRI data using spherical deconvolution. Neuroimage 2004;23:1176-85 CrossRef Medline

32. Tournier JD, Calamante F, Connelly A. Robust determination of the fibre orientation distribution in diffusion MRI: non-negativity constrained super-resolved spherical deconvolution. Neuroimage 2007;35:1459-72 CrossRef Medline

33. Tournier JD, Yeh CH, Calamante F, et al. Resolving crossing fibres using constrained spherical deconvolution: validation using diffusion-weighted imaging phantom data. Neuroimage 2008;42:617-25 CrossRef Medline
34. Kristo G, Leemans A, Raemaekers M, et al. Reliability of two clinically relevant fiber pathways reconstructed with constrained spherical deconvolution. Magn Reson Med 2013;70:1544-56 CrossRef Medline

35. Farquharson S, Tournier JD, Calamante F, et al. White matter fiber tractography: why we need to move beyond DTI. J Neurosurg 2013; 118:1367-77 CrossRef Medline

36. Jeurissen B, Leemans A, Tournier JD, et al. Investigating the prevalence of complex fiber configurations in white matter tissue with diffusion magnetic resonance imaging. Hum Brain Mapp 2013;34: 2747-66 CrossRef Medline

37. Movement Disorder Society Task Force on Rating Scales for Parkinson's Disease. The Unified Parkinson's Disease Rating Scale (UPDRS): status and recommendations. Mov Disord 2003;18:738-50 CrossRef Medline

38. Toiviainen-Salo S, Mäkitie O, Mannerkoski M, et al. ShwachmanDiamond syndrome is associated with structural brain alterations on MRI. Am J Med Genet A 2008;146A:1558-64 CrossRef Medline

39. Leemans A, Jeurissen B, Sijbers J, et al. ExploreDTI: a graphical toolbox for processing, analyzing, and visualizing diffusion MR data. In: Proceedings of the Scientific Meeting and Exhibition of the International Society for Magnetic Resonance in Medicine, Honolulu, Hawaii. April 18-24, 2009; 17:3537

40. Leemans A, Jones DK. The B-matrix must be rotated when correcting for subject motion in DTI data. Magn Reson Med 2009;61: 1336-49 CrossRef Medline

41. Irfanoglu MO, Walker L, Sarlls J, et al. Effects of image distortions originating from susceptibility variations and concomitant fields on diffusion MRI tractography results. Neuroimage 2012;61:275-88 CrossRef Medline

42. Westin CF, Maier SE, Mamata H, et al. Processing and visualization for diffusion tensor MRI. Med Image Anal 2002;6:93-108 CrossRef Medline

43. Vos SB, Jones DK, Jeurissen B, et al. The influence of complex white matter architecture on the mean diffusivity in diffusion tensor MRI of the human brain. Neuroimage 2012;59:2208-16 CrossRef Medline

44. Wiegell MR, Larsson HB, Wedeen VJ. Fiber crossing in human brain depicted with diffusion tensor MR imaging. Radiology 2000;217: 897-903 CrossRef Medline

45. Ennis DB, Kindlmann G. Orthogonal tensor invariants and the analysis of diffusion tensor magnetic resonance images. Magn Reson Med 2006;55:136-46 CrossRef Medline

46. Smith SM, Jenkinson M, Woolrich MW, et al. Advances in functional and structural MR image analysis and implementation as FSL. Neuroimage 2004;23(Suppl 1):S208-19 CrossRef Medline

47. Andersson JL, Sotiropoulos SN. Non-parametric representation and prediction of single- and multi-shell diffusion-weighted MRI data using Gaussian processes. Neuroimage 2015;122:166-76 CrossRef Medline

48. Winkler AM, Ridgway GR, Webster MA, et al. Permutation inference for the general linear model. Neuroimage 2014;92:381-97 CrossRef Medline

49. Paniagua Bravo A, Forkert ND, Schulz A, et al. Quantitative T2 measurements in juvenile and late infantile neuronal ceroid lipofuscinosis. Clin Neuroradiol 2013;23:189-96 CrossRef Medline

50. Tournier JD, Calamante F, Connelly A. Determination of the appropriate $b$ value and number of gradient directions for high-angularresolution diffusion-weighted imaging. NMR Biomed 2013;26: 1775-86 CrossRef Medline

51. Toselli B, Tortora D, Severino M, et al. Improvement in white matter tract reconstruction with constrained spherical deconvolution and track density mapping in low angular resolution data: a pediatric study and literature review. Front Pediatr 2017;5:182 CrossRef Medline

52. Bach M, Laun FB, Leemans A, et al. Methodological considerations on tract-based spatial statistics (TBSS). Neuroimage 2014;100: 358-69 CrossRef Medline 